\title{
RESPOSTAS ECOFISIOLOGICAS POR ESPÉCIES ARBÓREAS ACUMULADORAS DE FÓSFORO NA AMAZÔNIA
}

\author{
Patricia Chaves de Oliveira \\ Docente-pesquisadora, Doutora em Ciências Agrárias; Coordenadora do Laboratório de \\ Estudos de Ecossistemas Amazônicos \\ (http://laboratoriodeestudosamazonicos.blogspot.com), Universidade Federal do Oeste do \\ Pará (UFOPA), Avenida Marechal Rondom, s/n, Santarém, Pará, CEP 68.040-100; \\ pchaves@ufpa.br \\ Cláudio José Reis de Carvalho \\ Pesquisador, Doutor em Fisiologia de Plantas, EMBRAPA/CPATU, Avenida Perimetral, \\ s/n, Belém, Pará, CEP 66.000-100
}

\section{RESUMO}

Espécies Vegetais potencialmente acumuladores de fósforo (P) como Neea macrophylla e Cecropia palmata representam componentes de interesse no enriquecimento de capoeiras e em sistemas agroflorestais haja vista seu potencial em produzir mulch de melhor qualidade do que a maioria das espécies comuns em florestas secundárias na região Nordeste do Estado do Pará. Dessa forma, a importância em se conhecer os perfis fotossintéticos dessas espécies sob condições de campo e portanto seu potencial em formar biomassa poderá contribuir no entendimento das interações biofísicas entre planta (folha) e atmosfera sob condições limitantes de fósforo (P). Os resultados demonstraram que Cecropia palmata apresentou os maiores fluxos de $\mathrm{CO}_{2}$ do que demais espécies assim como transpiração e condutância estomática mantendo suas folhas com temperaturas mais baixas sinalizando uma estratégia de adaptação a períodos mais secos. A eficiência potencial fotossintética no uso de fósforo foi maior em Casearia arborea, espécie não acumuladora de fósforo.

PALAVRAS-CHAVE: fotossíntese, eficiência fotossintética no uso do P (EFUP), condutância estomática

\section{ANSWERS ECOPHYSIOLOGY BY ARBOREAL SPECIES PHOSPHORUS ACCUMULATION IN THE AMAZON}

\begin{abstract}
Phosphorus accumulative plant resources as Neea macrophylla and Cecropia palmata represents components of interest in the enrichment of fallow vegetation (capoeiras) and in agroforests systems seen its potential in producing mulch of better quality of majority common species in secondary forests in Northeast region of Pará. Of this form, the importance in knowing the photosyntetic profiles of these species under field conditions and therefore its potential to "capture" carbon will be able to contribute in the agreement of biophysics interactions between plant (leaf) and atmosphere under phosphorus stress. The results demonstrated that Cecropia palmata presented the higher $\mathrm{CO}_{2}$ flows of that too much species as well as evapotranspiration and stomatic conductance, keeping its leaves with
\end{abstract}


lower temperatures signaling an adaptation strategy to dry periods. The potencial photosynthetic Phosphorus-use efficiency was higher in Casearia arborea.

KEY-WORDS: photosynthesis, photosynthetic phosphorus-use efficiency (PUE), stomatic conductance. 


\section{RESPOSTAS ECOFISIOLOGICAS POR ESPÉCIES ARBÓREAS ACUMULADORAS DE FÓSFORO NA AMAZÔNIA}

\section{INTRODUÇÃO}

A assimilação de carbono (C) pela fotossíntese pode ser influenciada por déficits de $\mathrm{P}$ como foi demonstrado por Pieters et al (2001) em Nicotiana tabacum L., os quais observaram uma redução de $75 \%$ na assimilação de $\mathrm{C}$ em plantas mantidas sob estresse de $\mathrm{P}$ inorgânico, tanto sob baixas quanto altas concentrações de $\mathrm{CO}_{2}$. Ao mesmo tempo, os fosforilados intermediários e os conteúdos de ATP diminuíram enquanto o amido aumentou. Dessa forma, é de se esperar que em ambientes com baixos níveis de $\mathrm{P}$ no solo, como os latossolos amarelos da Região Bragantina no estado do Pará, que espécies comuns de florestas secundárias apresentem baixa assimilação de $\mathrm{CO} 2$.

Loustau et al (1999) também observaram um decréscimo nas respostas fotossintéticas em plântulas de Pinus pinaster Ait quando submetidas a deficiência de P. A taxa máxima de transporte de elétrons $\left(\mathrm{J}_{M}\right)$, a eficiência aparente quântica de transporte de elétrons $(\alpha)$ e a velocidade máxima de carboxilação pela RUBISCO $\left(\mathrm{V}_{\mathrm{m}}\right)$ reduziram com o aumento do déficit de P, da mesma forma que a eficiência fotoquímica do fotossistema II (PSII) foi reduzida sob baixos níveis do nutriente. Os autores ainda observaram uma tendência de redução da condutância estomática sob as mesmas condições. Contudo, tais resultados foram obtidos enquanto as plantas estavam numa fase ativa de crescimento, posto que à medida que cessava o crescimento ocorria uma atenuação dos efeitos da nutrição fosfórica sobre a $V_{m} e$ um aumento em $\alpha$ e $\mathrm{J}_{\mathrm{M}}$. Sendo assim, tais resultados sugerem que a fase ontogenética das espécies pode deixá-las mais susceptíveis ou não quanto às respostas fotossintéticas diante de condições de estresse por P nos solos.

A eficiência fotossintético-nutricional (EFN) potencial e cumulativa são importantes parâmetros no estudo de seleção de espécies tolerantes a baixos níveis de fertilidade do solo. Segundo Hiremath (2000), a EFN potencial (fotossíntese máxima/ teor de nutriente na folha) tende a decrescer com o aumento da longevidade das folhas. Por outro lado, a EFN acumulativa ( $\mathrm{C}$ assimilado durante todo o período de vida da folha/ total de nutrientes encontrado na folha) tende a aumentar com o aumento da longevidade foliar. Segundo o autor, houve respostas diferentes entre a EFN para $\mathrm{P}$ (fósforo) e para $\mathrm{N}$ (nitrogênio) em árvores de Cedrella odorata, Cordia alliodora e Hyeronima alchorneoides; no caso da EFN para P não houve variações entre as espécies, ao contrário da EFN para N. A correlação positiva que se observou entre o teor de $\mathrm{N}$ e a EFN, também pode ser observada por Hikosaka e Hirose (2000), em 8 espécies arbóreas, onde as correlações entre as concentrações de RuBPCase e concentração de $\mathrm{N}$ eram bem estreitas, assim como entre capacidade fotossintética e RuBPCase. Estes resultados sugerem que os níveis de $\mathrm{N}$ nas

plantas, ou a capacidade que elas têm em acumulá-lo em seus tecidos foliares influenciará de certa forma a EFN para este elemento; contudo a longevidade foliar e a massa foliar área não apresentaram correlações positivas com a EFN para o N.

Os baixos níveis de $\mathrm{N}$ e $\mathrm{P}$ nos solos sob vegetação secundária, como os da capoeira em estudo, poderiam comprometer a EFN para $\mathrm{P}$ e $\mathrm{N}$ nas 4 espécies estudadas? A hipótese de trabalho é de que plantas acumuladoras de $\mathrm{P}$ deveriam ter baixa EFN em comparação às plantas não acumuladoras de $\mathrm{P}$. 
A baixa variação encontrada na EFN entre as 8 espécies acima comentadas corrobora a afirmativa de que espécies que coabitam um mesmo ambiente apresentam EFN similares. Tal afirmativa, enfatiza que apenas os níveis de minerais de um determinado ambiente edáfico acabam por delinear um perfil de EFN homogêneo entre as espécies; contudo a diversidade vegetal e por conseguinte a fitossociologia deste ecossistema não são incorporadas nesta análise. Sendo assim, as estratégias específicas dos indivíduos diante da captação de recursos, no caso $\mathrm{N}$ e $\mathrm{P}$ em ambientes com déficit, acabam por exercer uma pressão temporal e espacial mútua dentro da comunidade vegetal, onde espécies com potencialidade em desenvolver associações micorrízicas por exemplo, acabariam acumulando mais $\mathrm{P}$ do que as demais, o que provavelmente influenciaria a EFN para o $\mathrm{P}$.

Parece então, que a evolução estrutural e funcional das florestas é fator decisivo nas variações da EFN das espécies ao longo do tempo e necessariamente a abordagem sistêmica deve prevalecer sobre a analítica.

Além disso, a evolução da arquitetura das copas das diferentes espécies e por conseguinte as variações nas irradiâncias espectrais, seriam outros fatores a influenciar a EFN, como demonstrou Rosati et al (1999), quando estudando Prunus pérsica L. Batsch. cv. Fantasia, observou uma menor EFN para o $\mathrm{N}$ em folhas localizadas na sombra do que naquelas ao sol.

Porém, quando os níveis de $\mathrm{N}$ eram baixos no solo, a EFN para o $\mathrm{N}$ era maior do que em ambientes com altos níveis de $\mathrm{N}$, o que de certa forma, caracteriza uma estratégia da espécie em estudo. Se por um lado a concentração de $N$ apresenta correlação positiva com a EFN para o $\mathrm{N}$, como será a correlação entre a concentração de $\mathrm{P}$ e a EFN para o $\mathrm{P}$ em ambientes com baixos níveis, como os solos sob as vegetações secundárias no Nordeste Paraense?

Halsted e Lynch (1996), estudando a eficiência fotossintética no uso de P, observaram não haver diferenças entre plantas $\mathrm{C}_{3}$ e $\mathrm{C}_{4}$, embora dentre as espécies observadas, a Brachiaria $s p$., que fixa carbono via Ciclo $\mathrm{C}_{4}$ foi mais eficiente no uso do $\mathrm{P}$, posto que aumentou a biomassa radicular sob situação de déficit do nutriente mantendo assim a alocação de $\mathrm{P}$ para o caule. Os autores ainda detectaram uma correlação negativa entre as taxas fotossintéticas foliares e as respostas de crescimento. Parece que esta é mais uma estratégia das plantas de minimizar o estresse de $\mathrm{P}$, onde o crescimento do sistema radicular é favorecido em detrimento da parte aérea e conseqüentemente a alocação de carbono no solo é beneficiada.

De acordo com Gamon et al (1997), a deficiência nutricional leva à uma redução do índice de refletância fotossintético $(531-570 \mathrm{~nm})$ bem como do índice de fluorescência , o qual é baseado na eficiência fotoquímica do fotossistema II, em 20 espécies, por eles estudadas. Em função da correlação positiva entre a eficiência no uso de radiação e o índice de refletância fotossintético ao meio dia em folhas ou dosséis a pleno sol, os autores sugerem que tal índice pode ser um indicador das variações nas taxas fotossintéticas.

A redução da absorção líquida de $\mathrm{CO}_{2}$ ao meio dia observada nas espécies estudadas, sobretudo nas perenes sempre-verdes e menos nas perenes decíduas e anuais; sempre estava acompanhada de um baixo índice de reflectância e aumento dos níveis de um pigmento fotoprotetor da xantofila, a zeaxantina. Contudo, os mesmos autores não observaram correlações positivas abaixo dos dosséis, entre o índice de reflectância fotossintético e a eficiência no uso da radiação, onde a baixa iluminação e até mesmo a sombra estão presentes, por ocasião da arquitetura da copa das espécies. Considerando os baixos níveis de $\mathrm{P}$ nos solos de vegetações secundárias, como as do presente estudo, poderiam estes 
influenciar o índice de reflectância e eficiência do uso de radiação em espécies não acumuladoras de $\mathrm{P}$ ? A hipótese de trabalho é de que, espécies não acumuladoras de $\mathrm{P}$, com níveis abaixo de $0,4 \mathrm{mg} / \mathrm{kg}$ de $\mathrm{P}$ em tecidos foliares desenvolvam baixa eficiência no uso de radiação e baixo índice de reflectância ao meio dia, do que espécies acumuladoras de $\mathrm{P}$, como Cecropia palmata e Neea sp. Contudo, a significância destas possíveis diferenças é que darão o perfil ecofisiologico das espécies.

Este estudo teve como objetivo avaliar o comportamento fotossintético de duas espécies potencialmente acumuladoras de $\mathrm{P}$, Neea macrophylla e Cecropia palmata em condições de déficit natural em floresta secundária em estágio inicial de regeneração bem como de Casearia arborea, espécie não acumuladora de P. A manipulação de seis variáveis, Radiação fotossinteticamente ativa (PAR), Transpiração, Condutância estomática, Temperatura da folha, Fotossíntese e Carbono interno nas folhas das três espécies estudadas e em três períodos climáticos diferentes (seco, chuvoso e de transição) permitiu verificar correlações entre as mesmas e ainda testar o efeito do período climático sobre a fotossíntese.

\section{MATERIAL E MÉTODOS}

A pesquisa descritiva se desenvolveu em floresta secundária com aproximadamente 6 anos de regeneração (sitio I), situada à $01^{\circ} 07.291^{\prime}$ S e $47^{\circ} 35.714^{\prime}$ WO no Município de Igarapé- Açú a Nordeste do Estado do Pará. O solo da área se caracterizava com baixa fertilidade, com $2 \mathrm{mg}$ de $\mathrm{P} . \mathrm{dm}^{-3}$ solo, baixas porcentagens de nitrogênio $(\mathrm{N})$ cerca de 0,03 $\%, \mathrm{PH}$ ácido, na faixa de 4.5 a 5.0 e concentrações expressivas de alumínio (Al) em torno de $0.5 \mathrm{cmol} . \mathrm{dm}^{-3}$ solo.

Foram selecionadas 3 árvores de Neea macrophylla e 3 de Cecropia palmata onde se tomaram 3 folhas/árvore para leitura dos seguintes parâmetros; Radiação fotossinteticamente Ativa (PAR, $\mu \mathrm{mol} / \mathrm{m}^{2} / \mathrm{s}$ ), Transpiração $\left(\mathrm{mmol} \mathrm{H}_{2} \mathrm{O} / \mathrm{m}^{2} / \mathrm{s}\right)$, Condutância estomática $\left(\mathrm{mmol} / \mathrm{m}^{2} / \mathrm{s}\right)$, Temperatura da folha $\left({ }^{\mathrm{o}} \mathrm{C}\right)$, Fotossíntese $\left(\mu \mathrm{mol} \mathrm{CO}_{2} / \mathrm{m}^{2} / \mathrm{s}\right)$ e teor de $\mathrm{CO} 2$ interno (ppm), através da utilização de um Analisador de Gás na região do Infra-Vermelho (IRGA) modelo CIRAS II/PPSystems .

A análise estatística se caracterizou pela construção de Matrizes de Correlação de Pearson para cada uma das três espécies estudadas a fim de observar o grau de correlação linear entre as variáveis, bem como Análises de Regressão para identificar o melhor ajuste não linear. A seguir Análises Multivariadas foram feitas através da aplicação do teste de Hotteling para comparação das seis médias relativa às seis variáveis de forma simultânea entre duas amostras, no caso duas espécies. E por último foi verificado o efeito do período climático, seco (novembro de 2003), chuvoso (janeiro de 2004) e de transição (maio de 2004) sobre a dinâmica das seis variáveis foliares ligadas ao processo fotossintético também a partir da aplicação do Teste de Hotteling onde as amostras a serem comparadas neste caso foram os diferentes períodos climáticos. O programa estatístico utilizado foi o BioEstat 3.0 (Ayres et al, 2003).

\section{RESULTADOS E DISCUSSÕES}

As análises de Regressão demonstraram comportamentos similares como era de se esperar quanto à dependência entre a condutância estomática e a Transpiração nas folhas das 3 espécies estudadas, conforme Fig. 1, 2 e 3 com modelos de dependência geométrica com 
coeficientes de determinação (R2) altos, 92,60\%, 67,96\% e 97,38\%, respectivamente para Neea macrophylla, Cecropia palmata e Casearia arborea.

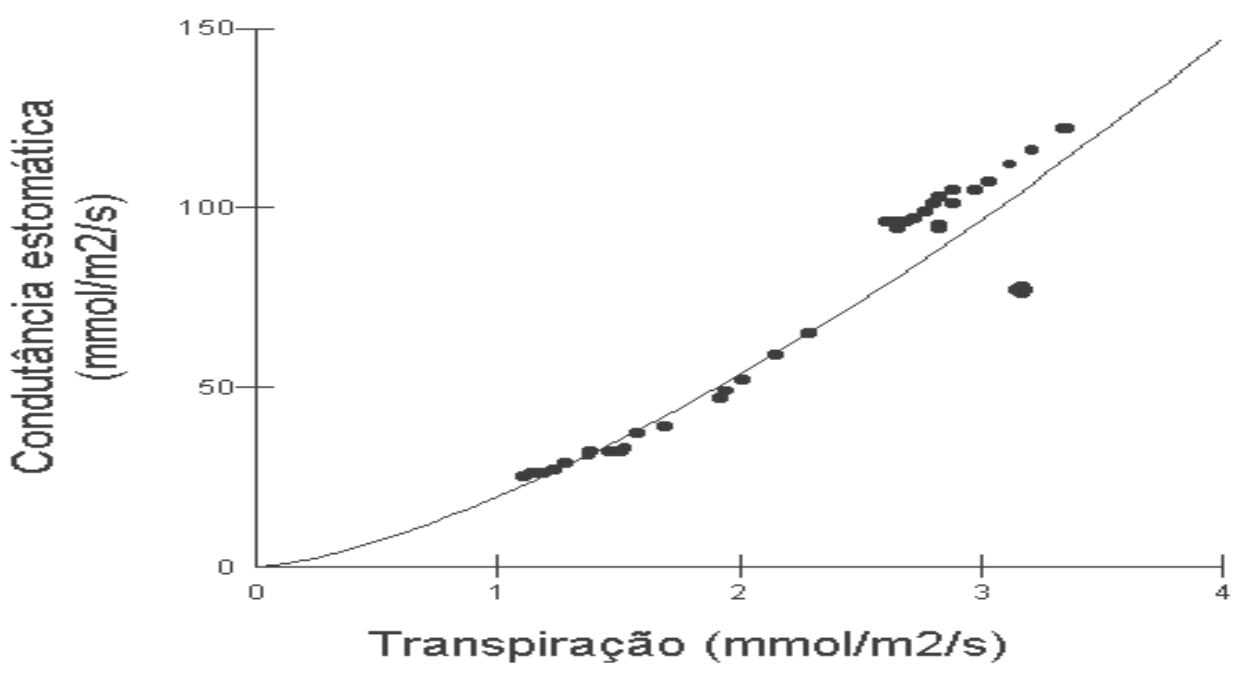

Figura 1 - Dependência com modelo Geométrico (R2=92,60\%) entre a condutância estomática $\left(\mathrm{mmol} / \mathrm{m}^{2} / \mathrm{s}\right)$ e a transpiração $\left(\mathrm{mmol} / \mathrm{m}^{2} / \mathrm{s}\right)$ em folhas de Neea macrophylla durante período seco em floresta secundária a Nordeste do Estado do Pará

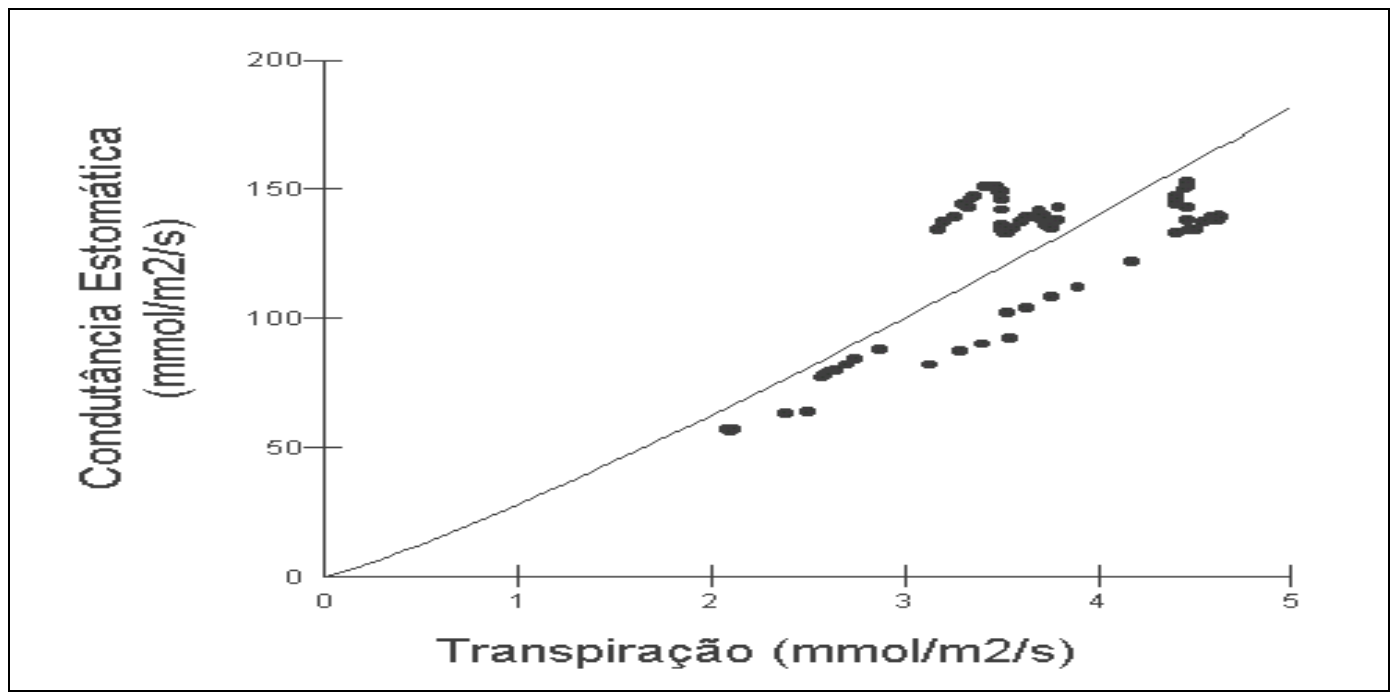

Figura 2 - Dependência com modelo Geométrico (R2=67,96\%) entre a condutância estomática $\left(\mathrm{mmol} / \mathrm{m}^{2} / \mathrm{s}\right)$ e a transpiração $(\mathrm{mmol} / \mathrm{m} 2 / \mathrm{s})$ em folhas de Cecropia palmata durante período seco em floresta secundária a Nordeste do Estado do Pará 


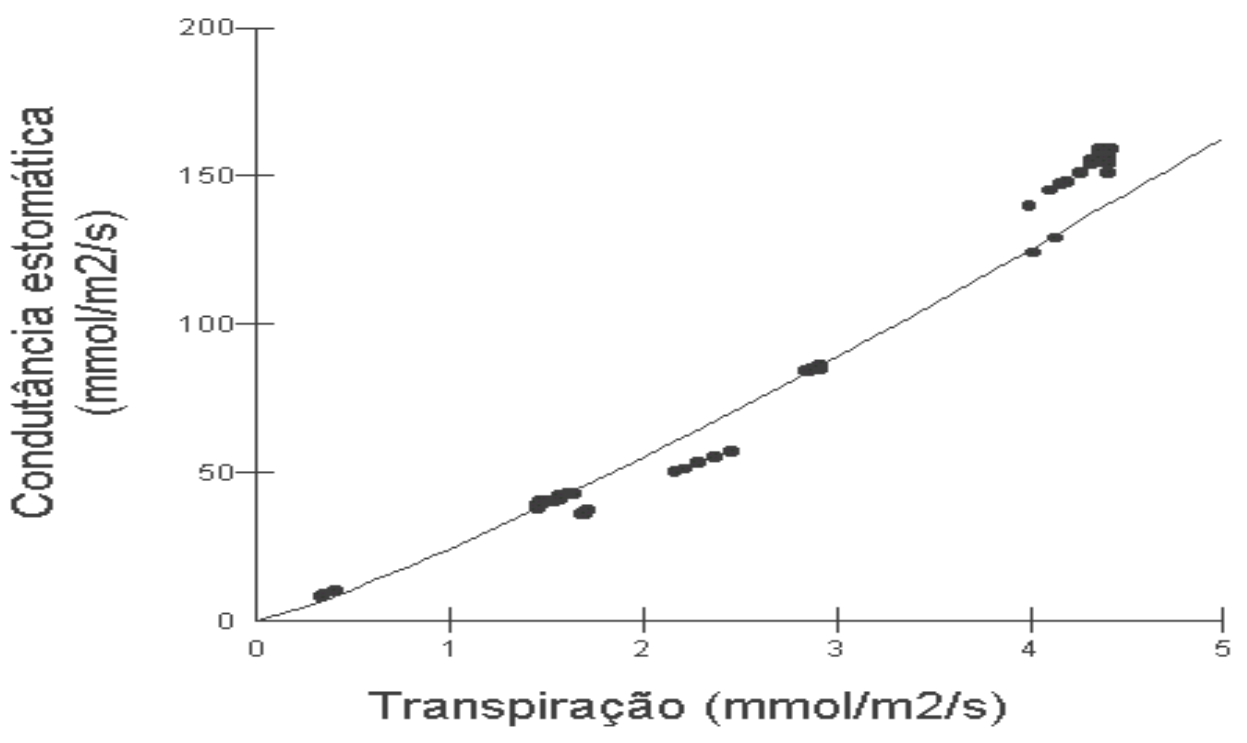

Figura 3- Dependência com modelo Geométrico (R2=97,38\%) entre a condutância estomática $\left(\mathrm{mmol} / \mathrm{m}^{2} / \mathrm{s}\right)$ e a transpiração $(\mathrm{mmol} / \mathrm{m} 2 / \mathrm{s})$ em folhas de Casearia arborea durante período seco em floresta secundária a Nordeste do Estado do Pará.

Dessa forma um aumento na condutância estomática levou a um aumento na transpiração para as três espécies estudadas. A condutância estomática nas folhas de Neea macrophylla por sua vez estabeleceu uma alta dependência $(\mathrm{R} 2=90.52 \%)$ com a fotossíntese $\left(\mu \mathrm{mol} \mathrm{CO}_{2}\right.$ $/ \mathrm{m}^{2} / \mathrm{s}$ ) conforme Fig. 2 onde um aumento na condutância estomática gerou um aumento na fotossíntese. Da mesma forma, a transpiração $\left(\mathrm{mmol} \mathrm{H}_{2} \mathrm{O} / \mathrm{m}^{2} / \mathrm{s}\right)$ também estabeleceu uma relação de alta dependência com a fotossíntese $(\mathrm{R} 2=91,11 \%)$ de acordo com a Fig. 5.

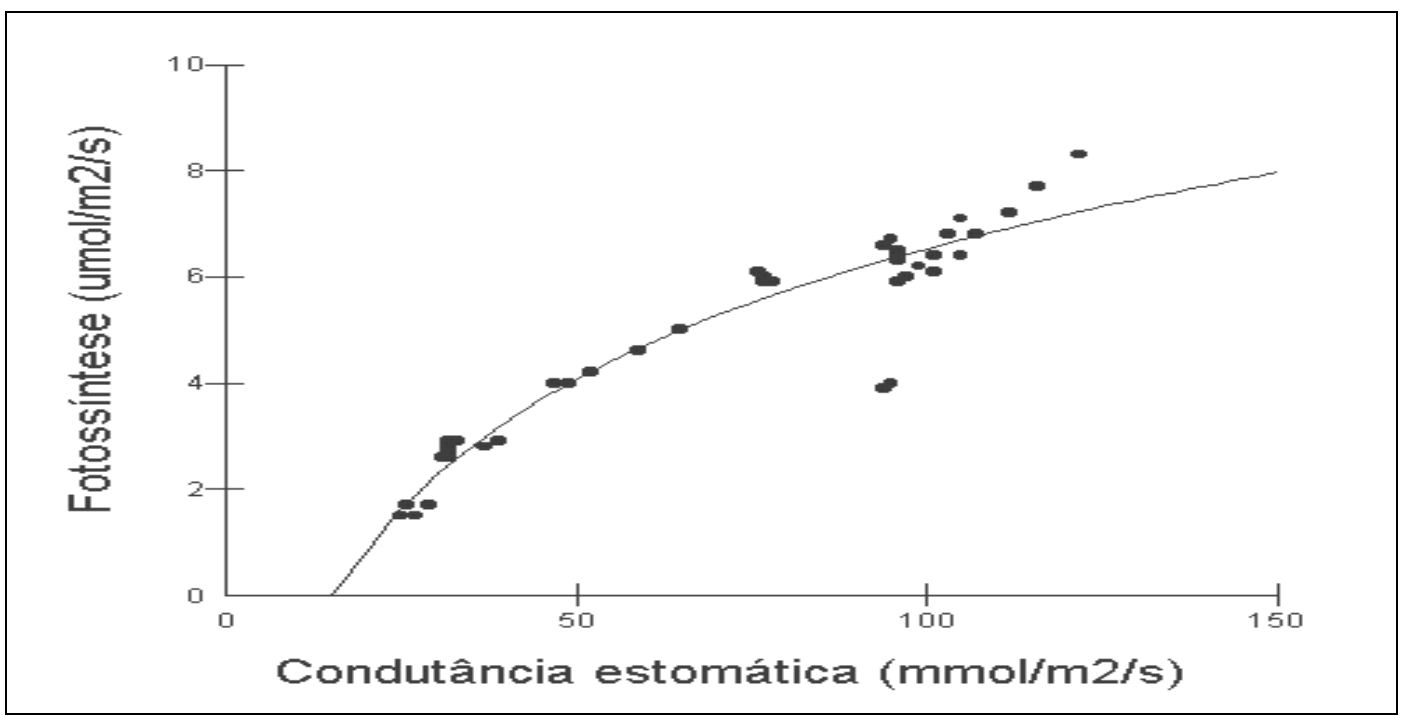

Figura 4- Dependência com modelo Logarítmico (R2=90,52\%) entre a fotossíntese $(\mu \mathrm{mol} / \mathrm{m} 2 / \mathrm{s})$ e a condutância estomática $\left(\mathrm{mmol} / \mathrm{m}^{2} / \mathrm{s}\right)$ em folhas de Neea macrophylla durante período seco em floresta secundária a Nordeste do Estado do Pará. 


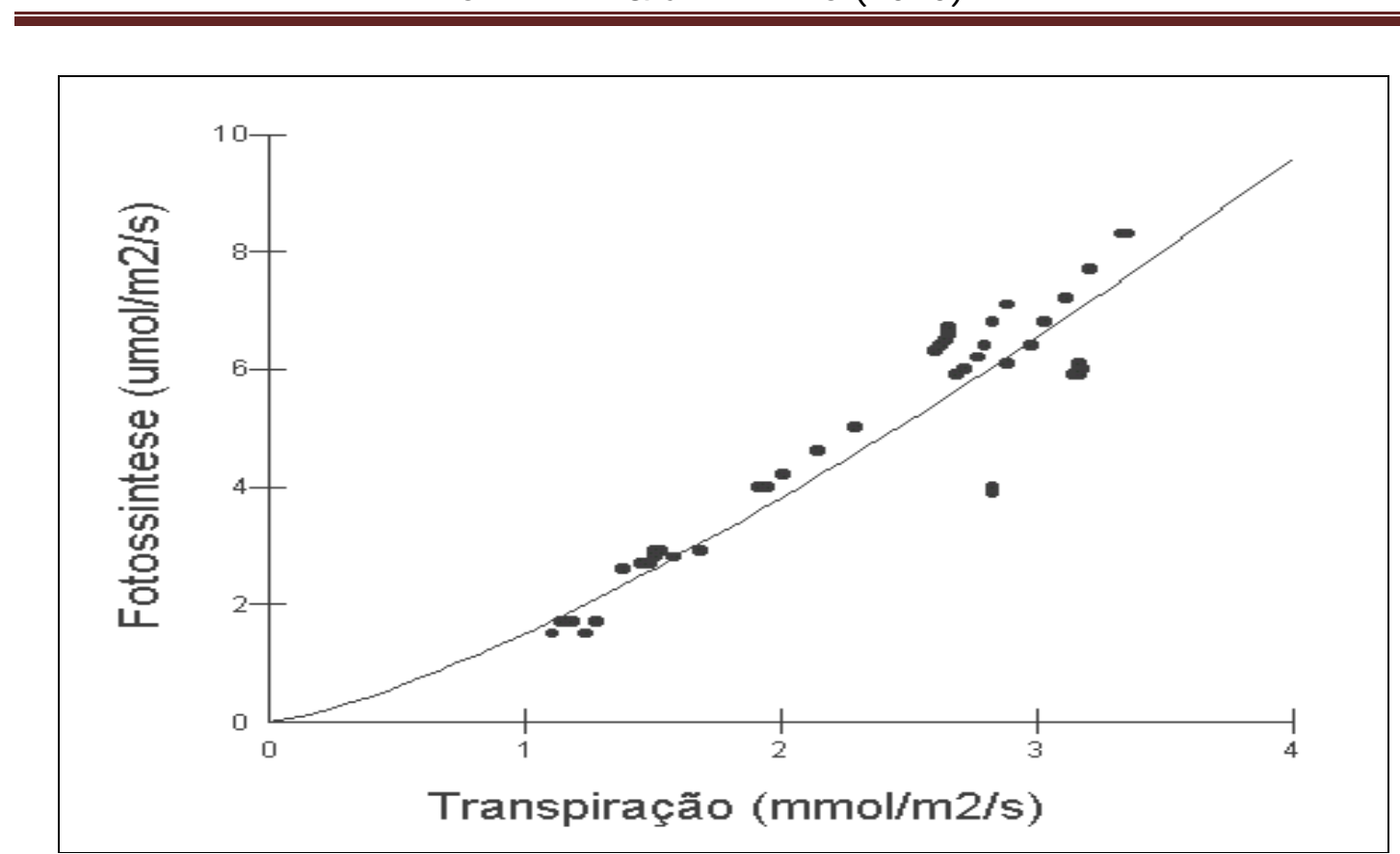

Figura 5 - Dependência com modelo Geométrico $(\mathrm{R} 2=91,11 \%)$ entre a fotossíntese $(\mu \mathrm{mol} / \mathrm{m} 2 / \mathrm{s})$ e a transpiração $\left(\mathrm{mmol} / \mathrm{m}^{2} / \mathrm{s}\right)$ em folhas de Neea macrophylla durante período seco em floresta secundária a Nordeste do Estado do Pará.

O controle da condutância estomática nas folhas como estratégia nos períodos mais prolongados de seca a fim de evitar o estresse por água nos tecidos é fundamental nestas florestas secundárias em estágio inicial de regeneração. Dentre as três espécies estudadas, Neea macrophylla foi à espécie que apresentou a menor condutância estomática nos três períodos climáticos (Fig. 6) sugerindo um controle maior na troca de gases, o que de certa forma é bom durante o período seco, pois evita o estresse por água, mas por outro lado regula a entrada de $\mathrm{CO}_{2}$ influenciando o processo fotossintético.

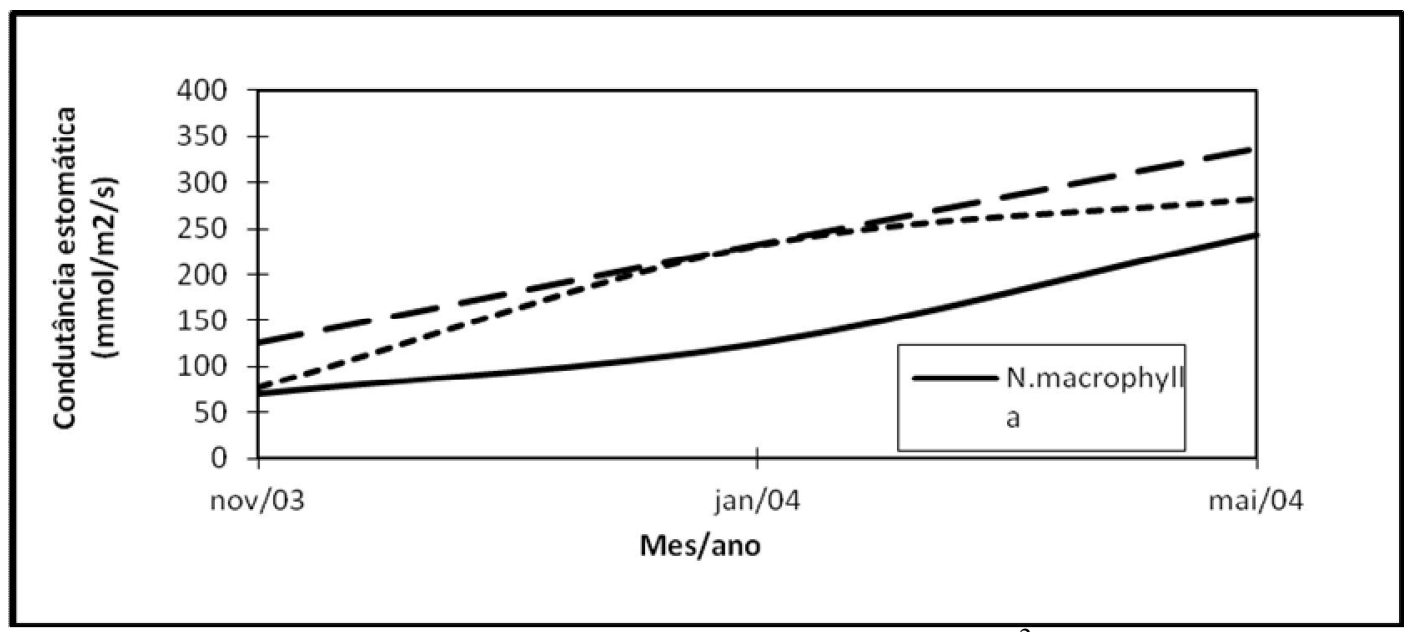

Figura 6 - Dinâmica da Condutância estomática $\left(\mathrm{mmol} / \mathrm{m}^{2} / \mathrm{s}\right)$ em folhas de Neea macrophylla, Cecropia palmata e Casearia arborea em 3 períodos climáticos, seco (novembro), chuvoso (janeiro) e de estiagem (maio) no Município de Igarapé-Açú. 
Folhas de Cecropia palmata opostamente à espécie Neea macrophylla mantiveram as maiores condutâncias estomáticas sugerindo maior tolerância ao déficit hídrico, haja vista que seus Potenciais Hídricos também foram superiores às outras duas espécies, o que de certa forma contribui para a entrada de $\mathrm{CO}_{2}$ e para o processo fotossintético. Em folhas de Cecropia palmata ficou nítida a relação de dependência logarítmica entre a concentração de $\mathrm{CO}_{2}$ interna (ppm) e a fotossíntese, onde o aumento da fotossíntese provocou uma redução na concentração interna de $\mathrm{CO}_{2}$ como mostra a Fig. 7.

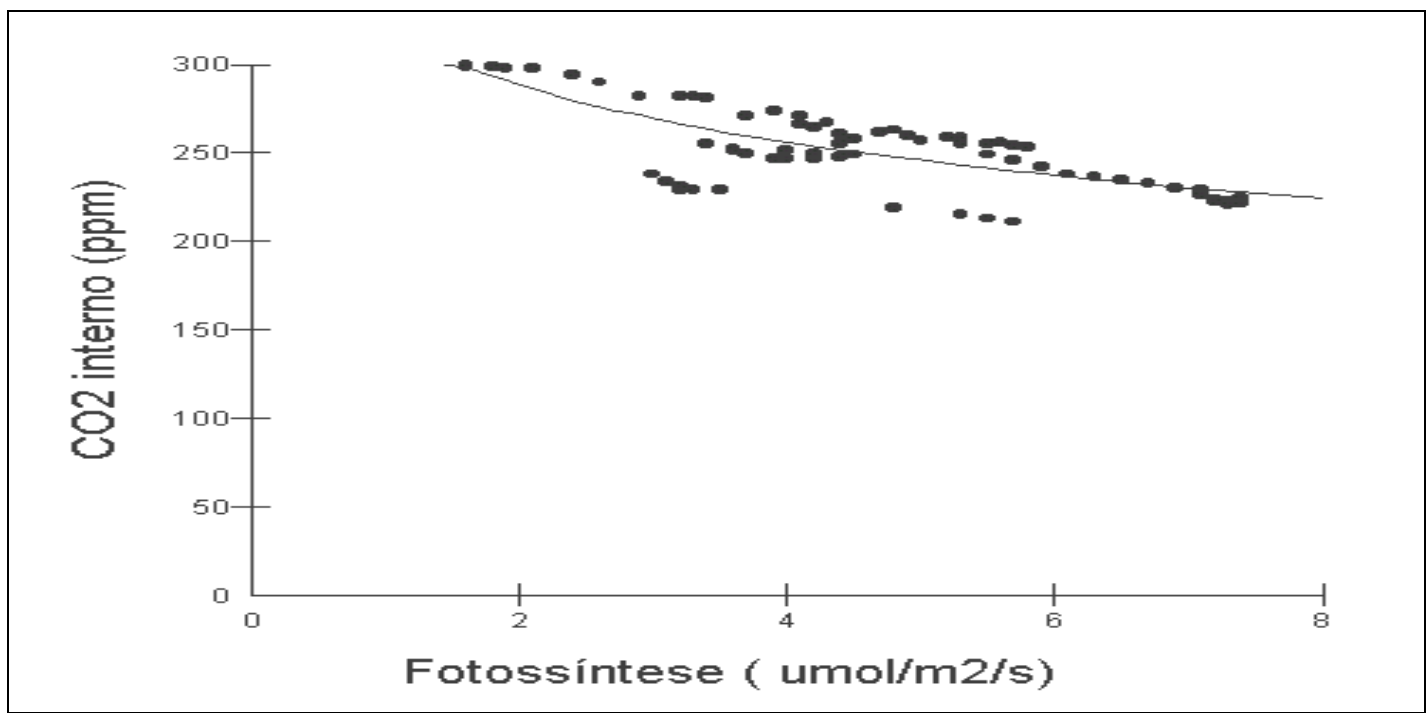

Figura 7 - Dependência com modelo Logarítmico (R2=59,55\%) entre a concentração interna de $\mathrm{CO}_{2}(\mathrm{ppm})$ e a fotossíntese $\left(\mu \mathrm{mol} / \mathrm{m}_{2} / \mathrm{s}\right)$ em folhas de Cecropia palmata durante período seco em floresta secundária a Nordeste do Estado do Pará.

Os resultados acerca da fotossíntese das três espécies estudadas revelaram que esta aumentou à medida que a condutância estomática aumentou conforme Fig. 8, 9 e 10.

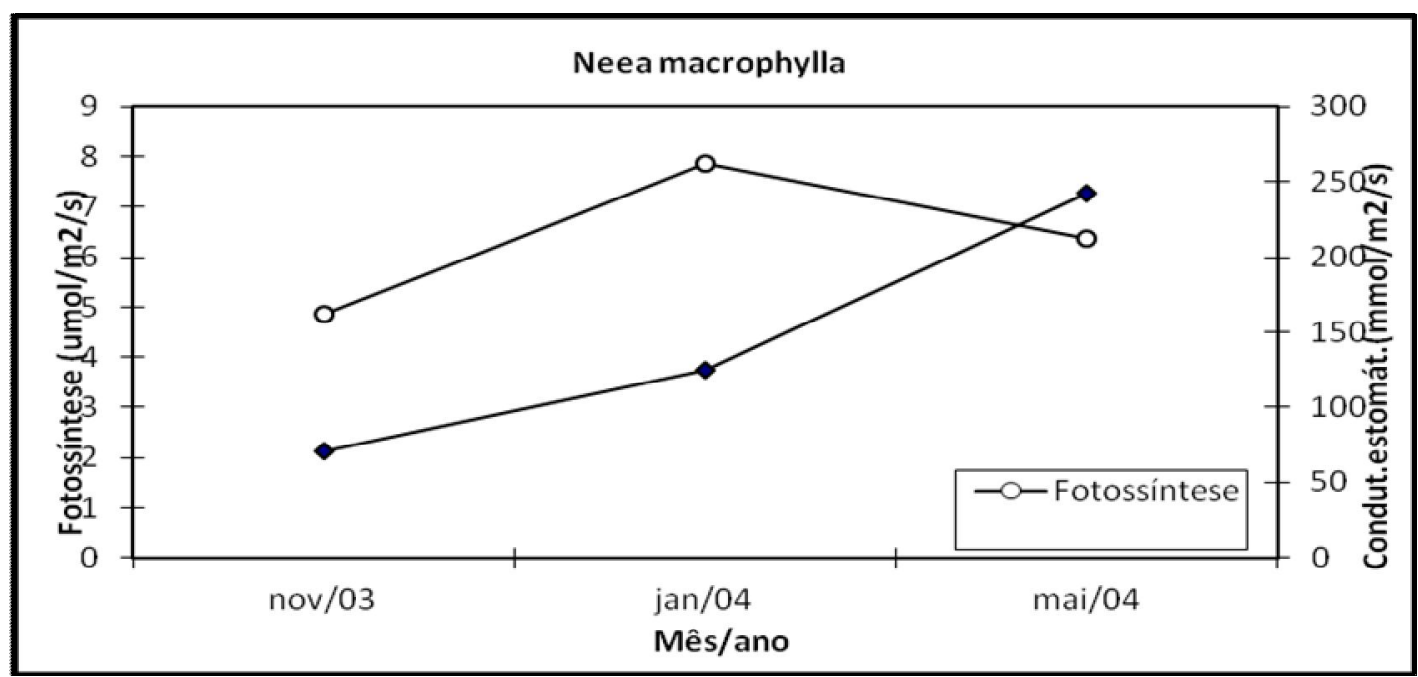

FIGURA 8 - Comportamento fotossintético $\left(\mu \mathrm{mol} / \mathrm{m}^{2} / \mathrm{s}\right)$ e estomático $\left(\mathrm{mmol} / \mathrm{m}^{2} / \mathrm{s}\right)$ em folhas de Neea macrophylla em 3 períodos climáticos; seco (novembro), chuvoso (janeiro) e de transição (maio) em floresta secundária no Município de Igarapé-Açú. 


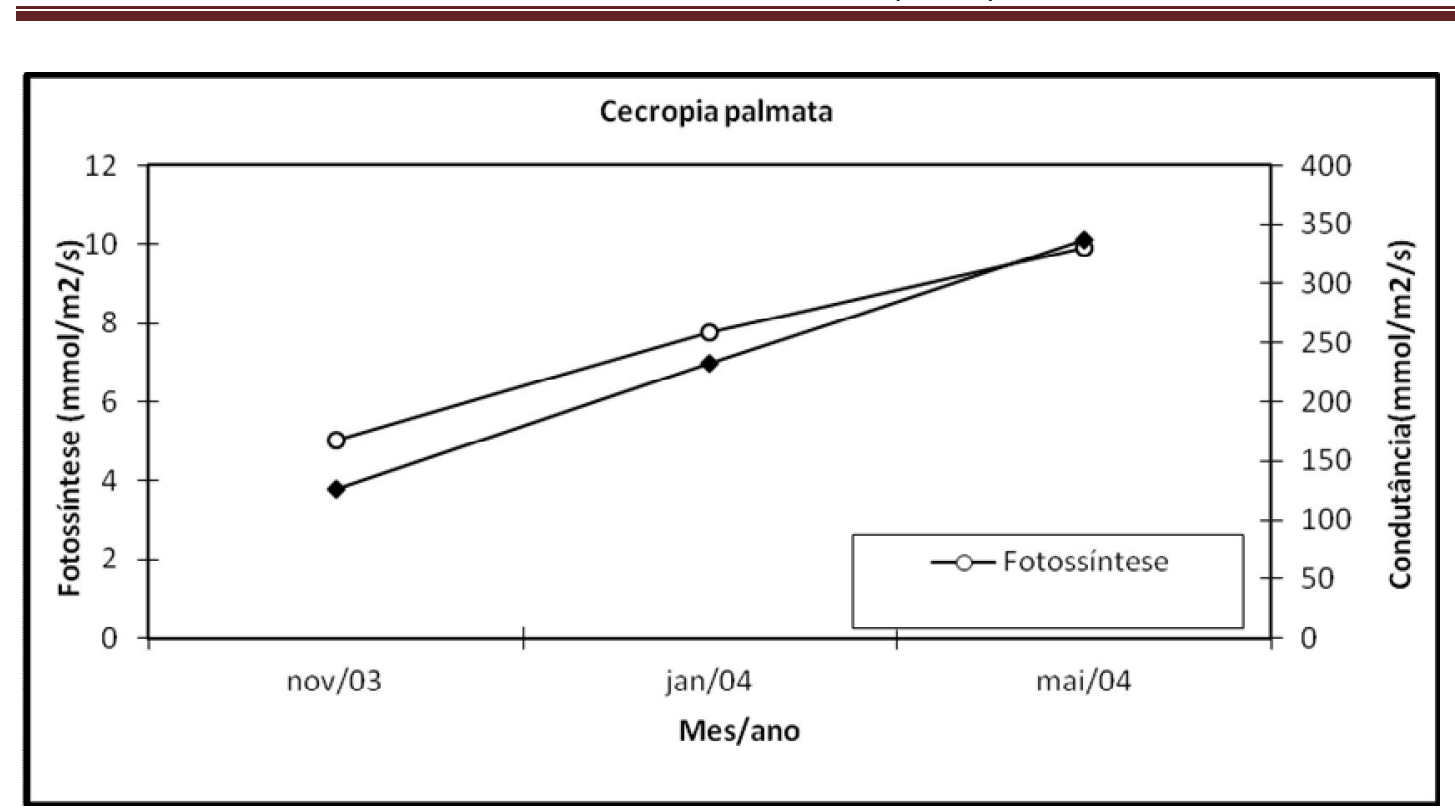

Figura 9 - Comportamento fotossintético $\left(\mu \mathrm{mol} / \mathrm{m}^{2} / \mathrm{s}\right)$ e estomático $\left(\mathrm{mmol} / \mathrm{m}^{2} / \mathrm{s}\right) \mathrm{em}$ folhas de Cecropia palmata em 3 períodos climáticos; seco (novembro), chuvoso (janeiro) e de tansição (maio) em floresta secundária no Município de Igarapé-Açú.

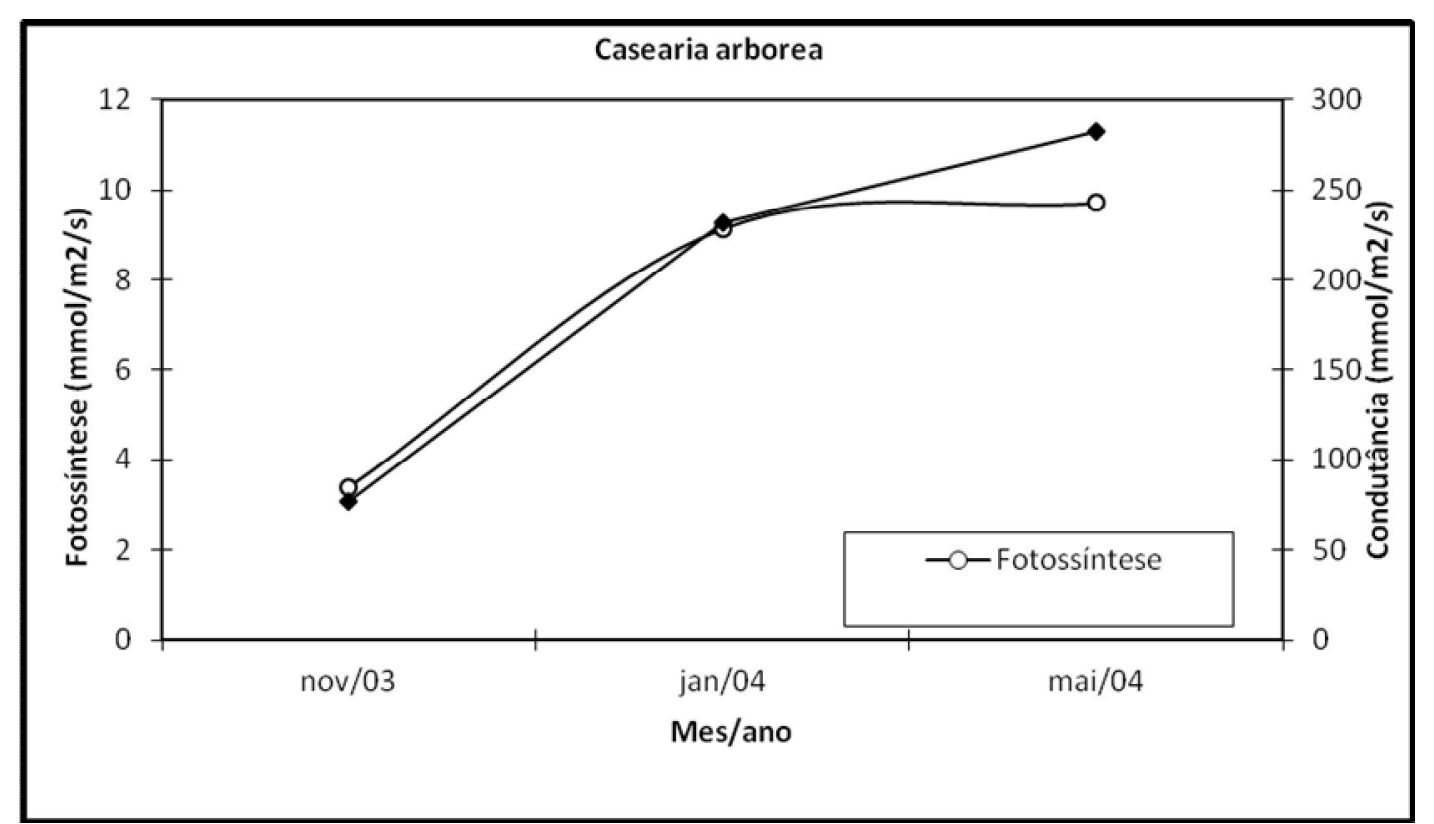

Figura 10 - Comportamento fotossintético $\left(\mu \mathrm{mol} / \mathrm{m}^{2} / \mathrm{s}\right)$ e estomático $\left(\mathrm{mmol} / \mathrm{m}^{2} / \mathrm{s}\right)$ em folhas de Casearia arborea em 3 períodos climáticos; seco (novembro), chuvoso (janeiro) e de transição (maio) em floresta secundária no Município de Igarapé-Açú.

No entanto a concentração interna de $\mathrm{CO}_{2}$ nas folhas e sua relação com a condutância estomática variou entre as espécies conforme mostraram as Fig. 11, 12 e 13. 


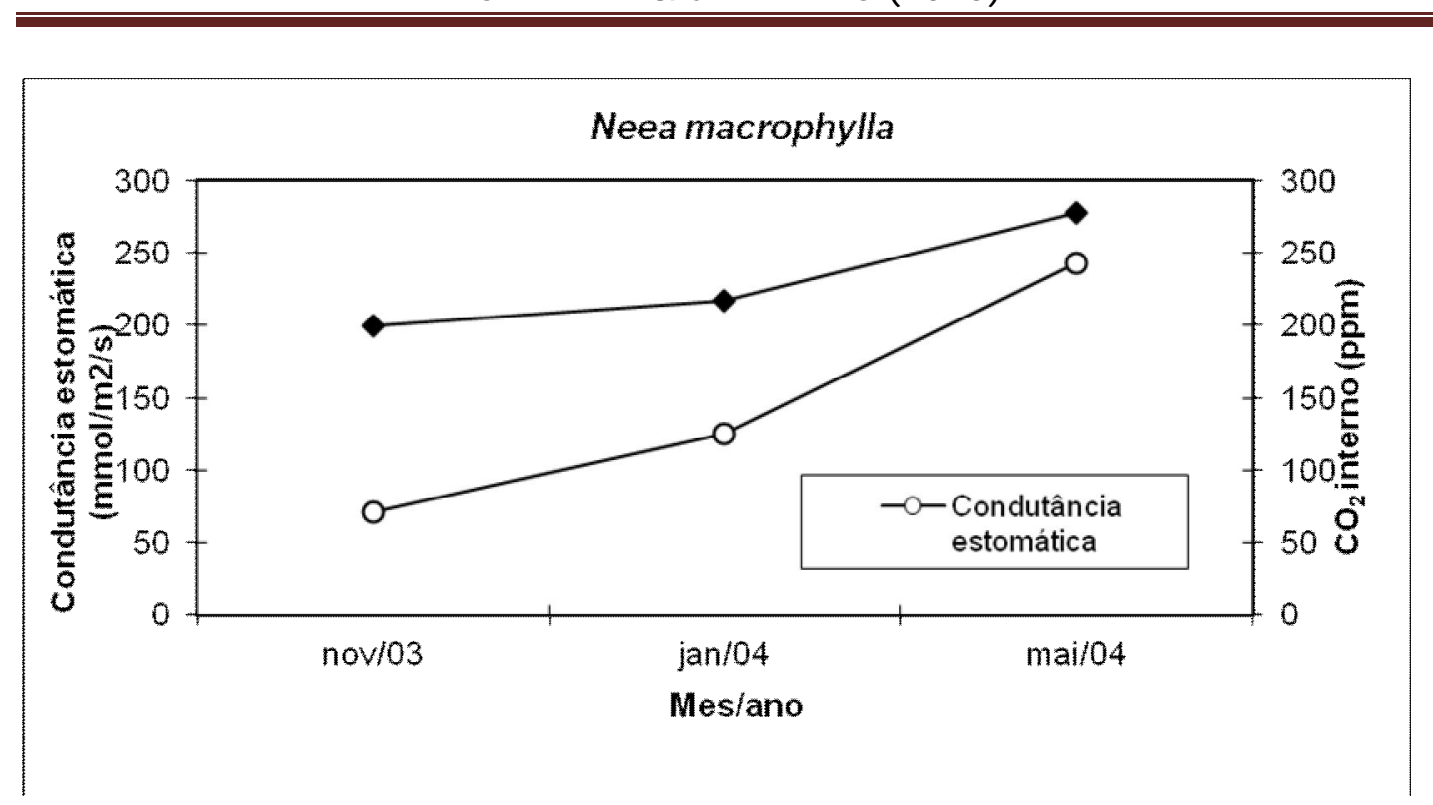

Figura 11 - Flutuações das concentrações do $\mathrm{CO}_{2}$ Interno (ppm) em função das variações na condutância estomática $\left(\mathrm{mmol} / \mathrm{m}^{2} / \mathrm{s}\right)$ em folhas de Neea macrophylla em três

Períodos distintos.

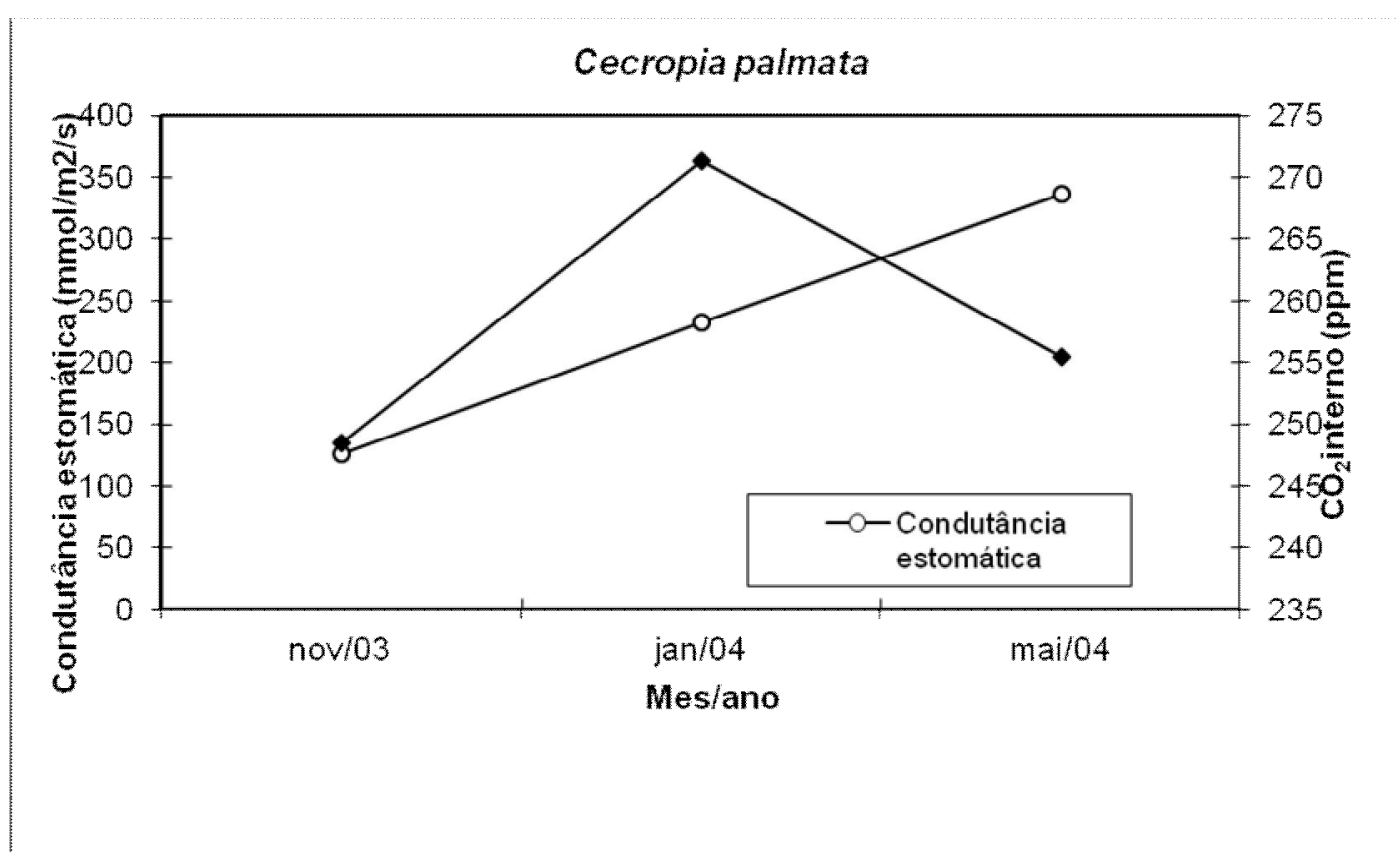

Figura 12 - Flutuações das concentrações do $\mathrm{CO}_{2}$ Interno (ppm) em função das variações na condutância estomática $\left(\mathrm{mmol} / \mathrm{m}^{2} / \mathrm{s}\right)$ em folhas de Cecropia palmata em três períodos distintos. 


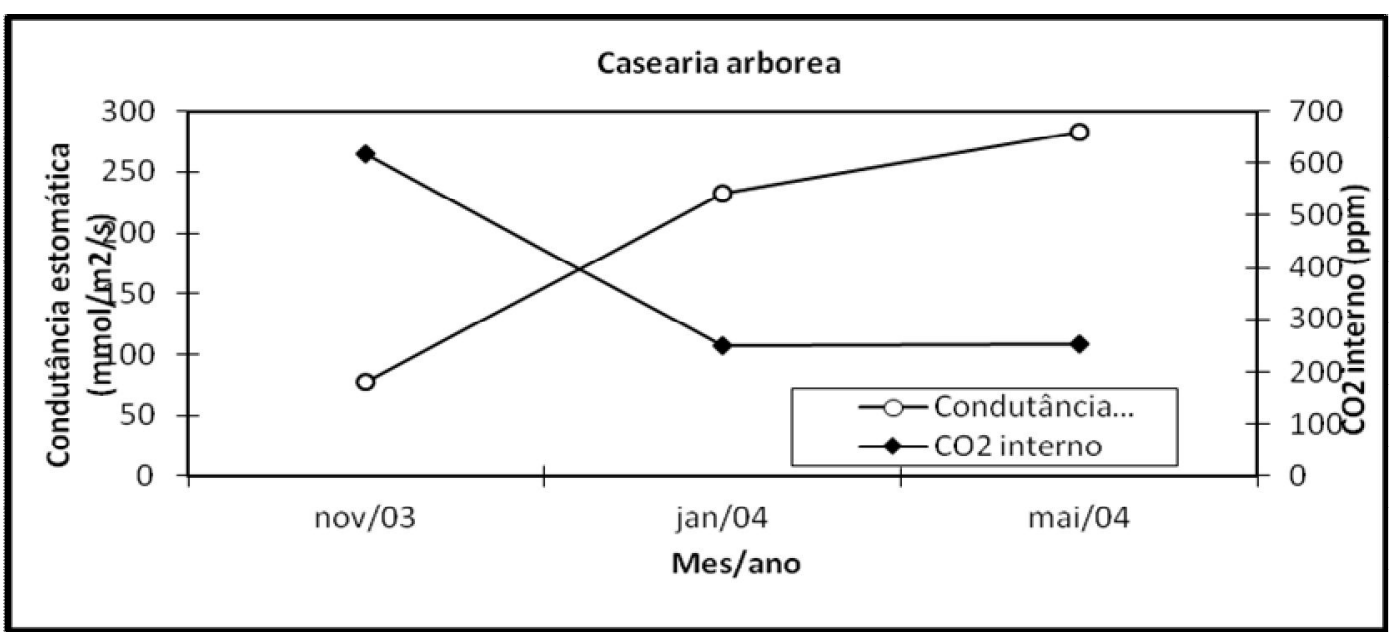

Figura 13 - Flutuações das concentrações do $\mathrm{CO}_{2}$ Interno (ppm) em função das variações na condutância estomática $\left(\mathrm{mmol} / \mathrm{m}^{2} / \mathrm{s}\right)$ em folhas de Casearia arborea em três períodos distintos.

Enquanto para folhas de Neea e Cecropia um aumento na condutância estomática levou a um aumento no teor de $\mathrm{CO}_{2}$ interno, para Casearia arborea o aumento na condutância estomática não evitou o declínio na concentração de $\mathrm{CO}_{2}$ interno, sugerindo atividade fotossintética, o que pode ser comprovado na Fig. 14, onde Casearia e Cecropia obtiveram as maiores Taxas Fotossintéticas.

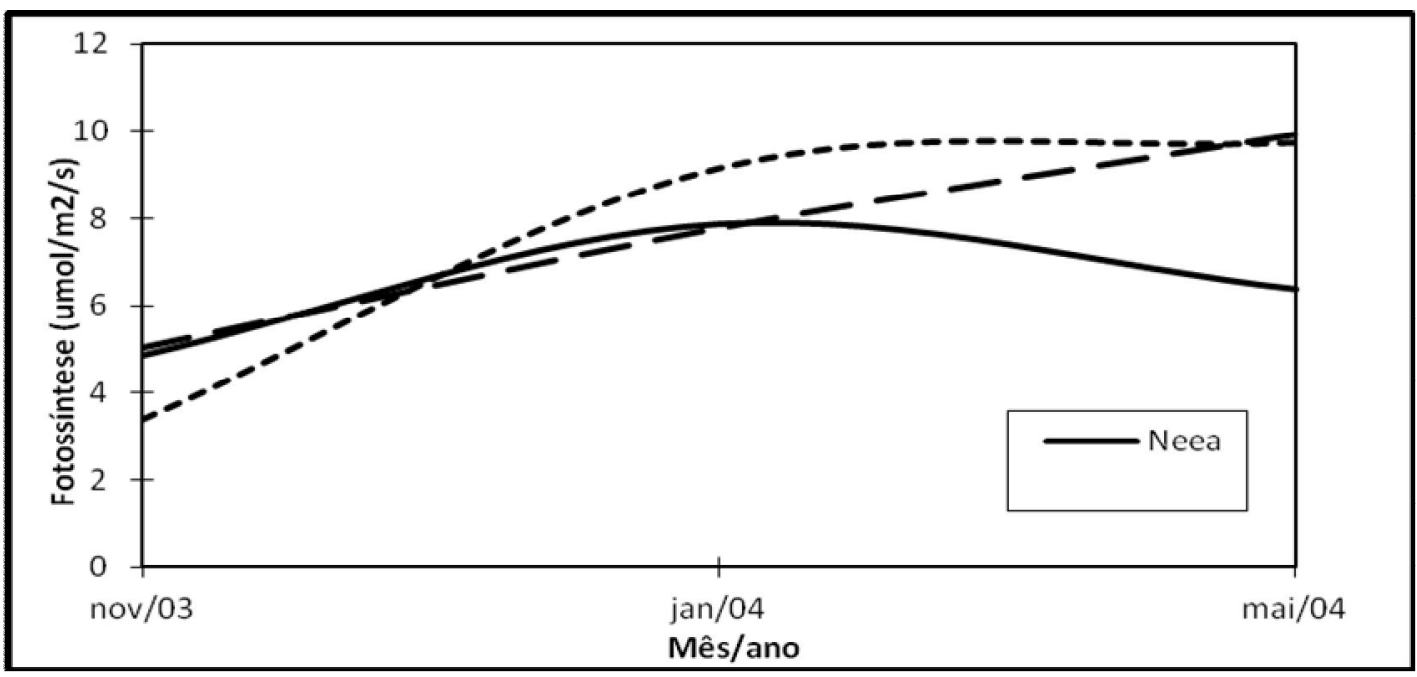

Figura 14 - Dinâmica do comportamento fotossintético em folhas de espécies acumuladoras de P, como Neea macrophylla e Cecropia palmata e não acumuladoras de P como Casearia arborea em 3 períodos climáticos, seco (novembro), chuvoso (janeiro) e de transição (maio) no Município de Igarapé-Açú, Pará, Brasil.

Considerando as duas espécies acumuladoras de fósforo (P), Neea macrophylla e Cecropia palmata, podemos dizer que Cecropia fotossintetiza um pouco mais do que Neea sobretudo no mês de transição, embora no período seco e chuvoso elas tiveram comportamento fotossintético muito semelhante. Neea macrophylla parece ser mais estável do que Cecropia palmata quanto ao fluxo de $\mathrm{CO}_{2}$ ao longo dos períodos climáticos 
enquanto Cecropia demonstrou maior plasticidade, contudo não mais do que Casearia arborea, que embora acumule pouco fósforo (P) em seus tecidos apresentou a maior amplitude quanto à Taxa Fotossintética.

O estudo de Correlação Linear entre as seis variáveis estudadas (Radiação Fotossinteticamente Ativa, Transpiração, Condutância estomática, Temperatura da folha, Fotossíntese e Teor de $\mathrm{CO}_{2}$ interno) em folhas de Neea macrophylla durante período chuvoso demonstrou através da Matriz de Correlação Linear de Pearson (Quadro 1) uma forte dependência linear com coeficiente de Pearson (r) igual a 0.97 entre a Radiação Fotossinteticamente Ativa (PAR) que insidia sobre as folhas e a Temperatura da folha com $P<0,001$ de que isso se deva ao acaso. A Radiação Fotossinteticamente Ativa também apresentou alta correlação linear, porém inversa com $\mathrm{r}=-0.96$ e $P=0,001$ com a concentração interna de $\mathrm{CO}_{2}$ sugerindo que com o aumento da PAR ocorre a redução do $\mathrm{CO}_{2}$ interno que deve estar sendo capturado pela Ribulose Bifosfato Carboxilase na fase fotoquímica da fotossíntese. Quanto às folhas de Cecropia palmata, a Matriz de Correlação Linear (Quadro 1) demonstrou correlações entre a PAR e a Fotossíntese $(r=0.84)$ e entre a Transpiração e a temperatura da folha $(\mathrm{r}=0.91)$ o que sugere que a Transpiração funciona como um indicador na regulação da temperatura da folha e isto por sua vez só foi possível graças às boas condutâncias estomáticas da espécie. Quanto à Casearia arbórea, a Matriz de Correlação construída (Quadro 1) demonstrou altas correlações entre Transpiração e Fotossíntese (r=0.82) e PAR e Transpiração ( $r=0.92)$. 
QUADRO 1 - Matriz de Correlação Linear entre seis variáveis (var 1-Radiação Fotossinteticamente Ativa, PAR; var 2 Transpiração,TRANS; Var 3-Condutância estomática, GS; var 4- Temperatura da folha,LF; var 5-Fotossíntese,PN; e var6 -

Concentração interna de $\mathrm{Co}_{2} ; \mathrm{CI}$.) em folhas de Neea macrophylla, Cecropia palmata e Casearia arborea no período chuvoso (janeiro ) Igarapé-Açú, Pará, Brasil.

\begin{tabular}{|c|c|c|c|c|c|c|c|c|c|c|c|c|c|c|}
\hline Neea & 1 e 2 & 1 e 3 & 1 e 4 & 1 e 5 & 1 e 6 & 2 e 3 & 2 e 4 & 2 e 5 & 2 e 6 & 3 e 4 & 3 e 5 & 3 e 6 & 4 e 5 & 5 e 6 \\
\hline (pares) $=$ & 31 & 31 & 31 & 31 & 31 & 31 & 31 & 31 & 31 & 31 & 31 & 31 & 31 & 31 \\
\hline $\begin{array}{l}r \text { (Pearso } \\
=\end{array}$ & 0.665 & -0.211 & 0.977 & 0.49 & -0.96 & 0.527 & 0.69 & 0.86 & -0.534 & $4-0.23$ & 0.685 & 0.324 & 0.43 & -0.45 \\
\hline $\mathrm{R} 2=$ & 0.4423 & 30.044 & 0.954 & 0.24 & 0.93 & 0.278 & 0.48 & 0.73 & 0.285 & 0.05 & 0.469 & 0.105 & 0.185 & 0.2 \\
\hline$(p)=$ & 0 & 0.255 & 0 & 0.01 & 0 & 0.002 & 0 & 0 & 0.002 & 0.21 & 0 & 0.076 & 0.016 & 0.01 \\
\hline Cecropia & & & & & & & & & & & & & & \\
\hline $\begin{array}{l}\text { r (Pearso } \\
=\end{array}$ & 0.614 & 0.335 & 0.827 & 0.84 & -0.69 & 0.893 & 0.91 & 0.67 & -0.222 & 0.64 & 0.535 & 0.028 & 0.742 & -0.75 \\
\hline $\mathrm{R} 2=$ & 0.377 & 0.112 & 0.684 & 0.71 & 0.48 & 0.798 & 0.83 & 0.45 & 0.049 & 0.41 & 0.286 & $8 E-04$ & 0.551 & 0.57 \\
\hline$(p)=$ & 0 & 0.014 & 0 & 0 & 0 & 0 & 0 & 0 & 0.11 & 0 & 0 & 0.845 & 0 & 0 \\
\hline Casearia & & & & & & & & & & & & & & \\
\hline r (Pearso & 0.923 & 0.506 & 0.868 & 0.7 & -0.23 & 0.719 & 0.74 & 0.82 & -0.048 & 0.09 & 0.789 & 0.567 & 0.417 & -0.016 \\
\hline $\mathrm{R} 2=$ & 0.852 & 0.256 & 0.753 & 0.48 & 0.05 & 0.517 & 0.55 & 0.67 & 0.002 & 0.01 & 0.623 & 0.321 & 0.174 & 0.0003 \\
\hline$p=$ & 0 & 0.002 & 0 & 0 & 0.18 & 0 & 0 & 0 & 0.781 & 0.61 & 0 & 3E-04 & 0.011 & 0.9248 \\
\hline
\end{tabular}

A Análise Multivariada das seis variáveis acima mencionadas revelou através da aplicação do Teste de Hotteling que dentre as duas espécies acumuladoras de fósforo (P), Neea macrophylla e Cecropia palmata existem diferenças significativas considerando o conjunto avaliado com probabilidade $(P)$ igual a 0,001 de que isto se deva ao acaso conforme Quadro 2. Cecropia palmata apresentou transpiração e condutância estomáticas muito superiores às de Neea macrophylla, contudo a fotossíntese entre as mesmas pouco diferiu, 4.85 e 5.03 $\mu \mathrm{mol} \mathrm{CO} / \mathrm{m} 2 / \mathrm{s}$, respectivamente folhas de Neea e de Cecropia . 
QUADRO 2- Análise Multivariada (var 1=Radiação fotossinteticamente ativa, PAR; var 2=Transpiração,TRANS; var 3= Condutância estomática,GS; var 4= Temperatura da folha,LF; var 5=Fotossíntese,PN e var 6= Concentração interna de $\mathrm{Co}_{2} ; \mathrm{CI}$ ) através da aplicação do Teste de Hotteling entre amostras de folhas de Neea macrophylla e Cecropia palmata, entre Neea e Casearia e entre Cecropia e Casearia durante o período seco (novembro ).

\begin{tabular}{|c|c|c|c|c|c|c|}
\hline Neea X Cecropia & Var $1=P A R$ & Var 2=TRASN & Var $3=\mathrm{GS}$ & $\operatorname{Var} 4=\mathrm{LF}$ & $\operatorname{Var} 5=P N$ & Var $6=\mathrm{Cl}$ \\
\hline Amostra 1 (Neea): $\quad$ média $=$ & 813.044 & 2.342 & 70.67 & 37.9 & 4.85 & 200.2 \\
\hline Amostra 2 (Cecropia): média & 636.273 & 3.622 & 126.4 & 37.2 & 5.03 & 248.5 \\
\hline $\mathrm{T} 2$ (Hotteling) $=$ & 266.934 & & & & & \\
\hline$(p)=$ & 0 & --- & --- & --- & --- & --- \\
\hline Neea X Casearia & & -- & --- & --- & --- & --- \\
\hline Amostra 1 (Neea): $\quad$ média $=$ & 813.044 & 2.342 & 70.67 & 37.9 & 4.85 & 200.2 \\
\hline Amostra 2 (Casearia): média & 653.828 & 2.521 & 76.86 & 38 & 3.38 & 516.3 \\
\hline $\mathrm{T} 2$ (Hotteling) $=$ & 96.0276 & & & & & \\
\hline$(p)=$ & 0 & -- & -- & -- & -- & -- \\
\hline Cecropia X Casearia & & & & & & \\
\hline Amostra 1 (Cecropia): média & 636.273 & 3.622 & 126.4 & 37.2 & 5.03 & 248.5 \\
\hline Amostra 2 (Casearia): média & 653.828 & 2.521 & 76.86 & 38 & 3.38 & 516.3 \\
\hline $\mathrm{T} 2$ (Hotteling) $=$ & 70.9203 & & & & & \\
\hline$(p)=$ & 0 & --- & --- & --- & --- & --- \\
\hline
\end{tabular}

As maiores concentrações de $\mathrm{CO} 2$ interno foram encontradas em folhas de Cecropia, 248.5 ppm provavelmente decorrente das altas condutâncias estomáticas. Em relação a temperatura das folhas, Neea macrophylla é mais sensível pois atinge temperaturas de até $37.9^{\circ}$ enquanto Cecropia consegue se manter com temperatura um pouco mais baixa, $37.2^{\circ}$ provavelmente decorrente da alta transpiração relativa. Dessa forma, Cecropia palmata é superior a Neea macrophylla quanto ao processo fotossintético.

Quando comparamos Neea macrophylla e Casearia arborea quanto ao conjunto das seis variáveis relativas ao processo fotossintético, observamos de acordo com o Teste de Hotteling que existe diferença significativa entre estas duas espécies com $P<0,001$ conforme Quadro 2. O perfil da condutância estomática, evapotranspiração e temperatura foliar foi muito similar entre estas duas espécies, porém, a fotossíntese foi maior em Neea $(4.85 \mu \mathrm{mol}$ 
$\mathrm{CO}_{2} / \mathrm{m}^{2} / \mathrm{s}$ ) e menor em Casearia arborea (3.38 $\mu \mathrm{mol} \mathrm{CO}_{2} / \mathrm{m}^{2} / \mathrm{s}$ ) embora as maiores concentrações de CO2 interno terem sido encontradas em Casearia (616.3 PPM) sugerindo baixa eficiência fotossintética desta espécie. E finalmente quando comparamos Cecropia e Casearia também observamos diferenças significativas, sendo que Casearia além de não acumular fósforo em seus tecidos, não é eficiente fotossinteticamente em relação à Neea $e$ Cecropia no mês estudado (novembro de 2003).

Os resultados relativos ao efeito do período climático seco (novembro de 2003), chuvoso (janeiro de 2004) e de transição (maio de 2004) sobre a dinâmica das seis variáveis estudadas para cada uma das três espécies revelou que o metabolismo foliar de Neea macrophylla (Quadro 3) no período seco é diferente significativamente $(P<0,001)$ do período chuvoso onde um contexto com menor PAR como no período chuvoso propiciou menor transpiração, menor temperatura foliar porém, maior condutância estomática e maior fotossíntese $\left(7.86 \mu \mathrm{mol} \mathrm{CO}_{2} / \mathrm{m}^{2} / \mathrm{s}\right)$ do que no período seco (novembro) estando portanto de acordo com Fortini et al (2003) que também encontrou os maiores fluxos de $\mathrm{CO}_{2}$ em Miconia ciliata nos períodos de transição e chuvoso; sugerindo que a água e não a luz é fator limitante nos processos fotossintéticos de espécies comuns nesta região. Da mesma forma quando comparamos a dinâmica das variáveis estudadas em folhas de Neea macrophylla entre o período climático seco $\mathrm{X}$ transição e o chuvoso $\mathrm{X}$ transição observamos diferenças significativas entre os mesmos, sinalizando a flexibilidade do padrão fotossintético nesta espécie frente às condições de luz, água e nutrientes.

QUADRO 3- Análise Multivariada, (var 1=Radiação fotossinteticamente ativa, PAR; var 2=Transpiração,TRANS; var 3= Condutância estomática,GS; var 4= Temperatura da folha,LF; var 5=Fotossíntese, PN e var 6= Concentração interna de $\mathrm{Co}_{2} ; \mathrm{CI}$ ) através da aplicação do Teste de Hotteling entre amostras de novembro (período seco), janeiro (período chuvoso) e maio (período de transição) em folhas de Neea macrophylla.

\begin{tabular}{|c|c|c|c|c|c|c|}
\hline $\begin{array}{l}\text { Neea macrophylla } \\
\text { NOVEMBROXJANEIRO }\end{array}$ & Var $1=$ PAR & $\begin{array}{l}\text { Var } \\
2=\text { TRANS }\end{array}$ & $\operatorname{Var} 3=\mathrm{GS}$ & Var 4=LH & $\operatorname{Var} 5=\mathrm{PN}$ & $\operatorname{Var} 6=\mathrm{CI}$ \\
\hline Amostra 1 (novembro): média & 813.044 & 2.342 & \begin{tabular}{|l|l}
70.67 \\
\end{tabular} & 37.9 & 4.85 & 200.2 \\
\hline Amostra 2 (janeiro): $\quad$ média & 620.936 & 1.961 & 125.2 & 32.4 & 7.86 & 217.4 \\
\hline $\mathrm{T} 2($ Hotteling $)=$ & 753.766 & --- & --- & --- & --- & --- \\
\hline$(p)=$ & 0 & --- & --- & --- & --- & --- \\
\hline \multicolumn{7}{|l|}{ NOVEMBROX MAIO } \\
\hline Amostra 1 (novembro): média & 813.044 & 2.342 & 70.67 & 37.9 & 4.85 & 200.2 \\
\hline Amostra 2 (maio) : média = & 596.366 & 3.119 & 224.9 & 33.4 & 6.62 & 268.1 \\
\hline $\mathrm{T} 2$ (Hotteling) $=$ & 1332.01 & --- & --- & --- & --- & --- \\
\hline$(p)=$ & 0 & --- & --- & --- & --- & --- \\
\hline \multicolumn{7}{|l|}{ JANEIROX MAIO } \\
\hline Amostra 1 (janeiro): média & 620.936 & 1.961 & 125.2 & 32.4 & 7.86 & 217.4 \\
\hline Amostra 2 (maio): média & 596.366 & 3.119 & 224.9 & 33.4 & 6.62 & 268.1 \\
\hline T2 (Hotteling) & 218.532 & & & & & \\
\hline (p) & 0 & & & & & \\
\hline
\end{tabular}

Quanto aos resultados acerca do efeito do período climático sobre a dinâmica das variáveis ligadas ao processo fotossintético em folhas de Cecropia palmata estes demonstraram haver diferença significativa entre o mês de novembro de 2003 e o de janeiro de 2004 conforme Quadro 4. 
QUADRO 4- Análise Multivariada, (var 1=Radiação fotossinteticamente ativa, PAR; var 2=Transpiração,TRANS; var 3= Condutância estomática,GS; var 4= Temperatura da

folha,LF; var 5=Fotossíntese, PN e var 6= Concentração interna de $\mathrm{Co}_{2} ; \mathrm{CI}$ ) através da aplicação do Teste de Hotteling entre amostras de novembro (período seco); janeiro (período chuvoso e maio (transição) em folhas de Cecropia palmata.

\begin{tabular}{|c|c|c|c|c|c|c|}
\hline Cecropia palmata & & & & & & \\
\hline NOVEMBROX JANEIRO & Var $1=\mathrm{PAP}$ & Var 2=TRAN & Var 3=G & $\operatorname{Var} 4=\mathrm{LF}$ & F Var 5=P & Var $6=$ \\
\hline Amostra 1 (novembro/2003): média & 636.273 & 3.622 & 126.4 & 37.2 & 5.03 & 248.5 \\
\hline Amostra 2 (janeiro/2004): $\quad$ média $=$ & 492.151 & 2.313 & 232.8 & 30.6 & 7.77 & 271.3 \\
\hline $\mathrm{T} 2$ (Hotteling) $=$ & 1215.06 & & & & & \\
\hline$(p)=$ & 0 & --- & --- & --- & --- & --- \\
\hline \multicolumn{7}{|l|}{ NOVEMBROX MAIO } \\
\hline Amostra 1 (novembro/2003): média & 636.273 & 3.622 & 126.4 & 37.2 & 5.03 & 248.5 \\
\hline Amostra 2 (maio/2004): média & 1155.17 & 4.933 & 352.1 & 35.5 & 10.5 & 252.5 \\
\hline $\mathrm{T} 2($ Hotteling $)=$ & 5609.57 & --- & & & & \\
\hline$(p)=$ & 0.6169 & --- & --- & --- & --- & --- \\
\hline \multicolumn{7}{|l|}{ JANEIRO X MAIO } \\
\hline Amostra 1 (janeiro): $\quad$ média $=$ & 492.151 & 2.313 & 232.8 & 30.6 & 7.77 & 271.3 \\
\hline Amostra 2 (maio/2004): média & 1155.17 & 4.933 & 352.1 & 35.5 & 10.5 & 252.5 \\
\hline $\mathrm{T} 2$ (Hotteling) $=$ & 348.137 & --- & --- & & & \\
\hline$(p)=$ & 0 & --- & $\mid--$ & & & \\
\hline
\end{tabular}

Embora com menor PAR, menor temperatura foliar $\left(30^{\circ}\right)$ e conseqüente menor transpiração do que as folhas no mês de novembro, maior fotossíntese era obtida no período chuvoso, em parte devido ao aumento das condutâncias estomáticas. Contudo, não foram encontradas diferenças significativas de acordo com o Teste de Hotteling entre as amostras do período seco e de transição sinalizando um comportamento fotossintético mais homogêneo ao longo do ano para Cecropia palmata. As taxas fotossintéticas em folhas de Cecropia palmata foram maiores que as obtida em folhas de Miconia ciliata (Fortini et al, 2003). Quanto às folhas de Casearia arborea, estas apresentaram diferenças significativas quanto às variáveis ligadas ao processo fotossintético em função do período climático considerado conforme Quadro 5. 
QUADRO 5- Análise Multivariada, (var 1=Radiação fotossinteticamente ativa, PAR; var 2=Transpiração,TRANS; var 3= Condutância estomática,GS; var 4= Temperatura da folha,LF; var 5=Fotossíntese, PN e var 6= Concentração interna de $\mathrm{Co}_{2} ; \mathrm{CI}$ ) através da aplicação do Teste de Hotteling entre amostras de novembro (período seco); janeiro (período chuvoso) e maio em folhas de Casearia

\begin{tabular}{|c|c|c|c|c|c|c|}
\hline Casearia arborea & & & & & & \\
\hline NOVEMBROX JANEIRO & Var $1=$ PAR & $\operatorname{Var} 2=$ TRAN & $\operatorname{Var} 3=\mathrm{GS}$ & $\operatorname{Var} 4=\mathrm{L}^{-}$ & $\operatorname{Var} 5=\mathrm{PI}$ & $\operatorname{Var} 6=\mathrm{CI}$ \\
\hline Amostra 1 (novembro): média $=$ & 653.828 & 2.521 & 76.86 & 38 & 3.38 & 616.3 \\
\hline Amostra 2 (janeiro): média $=$ & 1069.5 & 3.106 & 231.9 & 32.7 & 9.14 & 249.7 \\
\hline $\mathrm{T} 2($ Hotteling $)=$ & 1008.3 & --- & --- & & & \\
\hline$(p)=$ & 0 & --- & --- & --- & --- & --- \\
\hline NOVEMBRO X MAIO & & & & & & \\
\hline Amostra 1 (novembro): média $=$ & 653.828 & 2.521 & 76.86 & 38 & 3.38 & 616.3 \\
\hline Amostra 2 (maio): média & 1256.67 & 3.752 & 281.7 & 34.6 & 9.86 & 250.5 \\
\hline$(\mathrm{p})=$ & 0 & --- & --- & -- & --- & --- \\
\hline JANEIRO X MAIO & & & & & & \\
\hline Amostra 1 (janeiro): média $=$ & 1069.5 & 3.106 & 231.9 & 32.7 & 9.14 & 249.7 \\
\hline Amostra 2 (maio): média & 1256.67 & 3.752 & 281.7 & 34.6 & 9.86 & 250.5 \\
\hline$(\mathrm{p})=$ & 0 & --- & --- & -- & -- & --- \\
\hline
\end{tabular}

Finalmente os resultados acerca da Eficiência Potencial Fotossintética no uso do fósforo (P) determinada pela razão entre a Fotossíntese e o Teor de fósforo $(\mathrm{P})$ nos tecidos foliares mostrou que Casearia arborea é a espécie mais eficiente no uso de fósforo quando levamos em consideração os fluxos de $\mathrm{CO}_{2}$, seguida de Cecropia palmata e Neea macrophylla (Fig. $15)$.

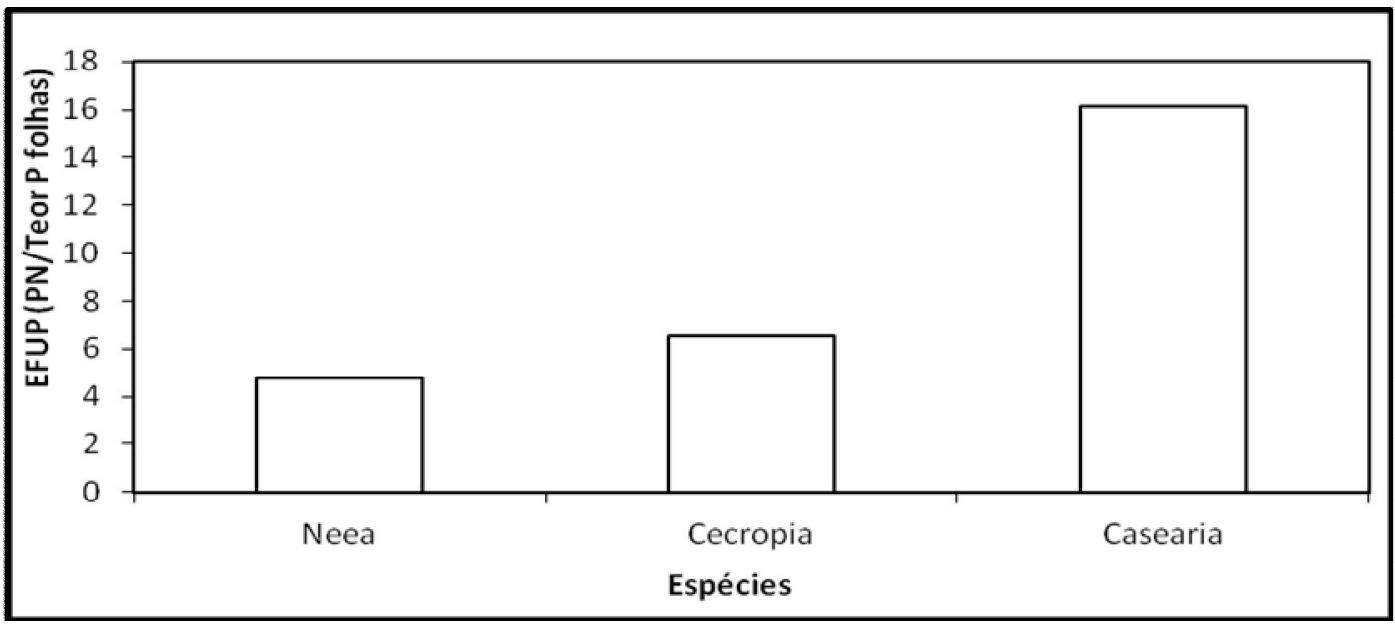

FIGURA 15 - Eficiência Potencial Fotossintética no uso de P (Fotossíntese/Teor de P nas folhas) em Neea macrophylla, Cecropia palmata e Casearia arborea. 


\section{CONCLUSÕES}

As espécies acumuladoras de $\mathrm{P}$ estudadas, Neea macrohpylla e Cecropia palmata encontradas em florestas secundárias em estágios iniciais e intermediários de regeneração apresentaram fotossíntese maior do que a espécie não acumuladora, Casearia arborea fato este essencial nos processos de crescimento e produção de biomassa rica em $\mathrm{P}$ em ambientes com déficit deste nutriente.

As correlações observadas entre Condutância estomática e Transpiração, Fotossíntese e CO2 interno, Fotossíntese e Condutância estomática e PAR e Temperatura da folha acabaram por delinear diferentes perfis no processo fotossintético de cada uma das espécies. Cecropia palmata apresentou as maiores condutâncias estomáticas e transpiração, regulando de certa forma melhor a temperatura da folha e o fluxo de $\mathrm{CO}_{2}$ culminando com taxas fotossintéticas maiores do que as demais espécies. Existiu nitidamente o efeito do período climático sobre a dinâmica das seis variáveis estudadas onde os maiores fluxos de $\mathrm{CO}_{2}$ ocorreram no período de transição com menor PAR e transpiração porém com maiores condutâncias estomáticas.

Se por um lado Neea e Cecropia não diferiram quanto ao teor de $\mathrm{P}$ em tecidos foliares, a fotossíntese por sua vez foi um fator diferencial entre as mesmas indicando Cecropia palmata com os maiores fluxos de $\mathrm{CO}_{2}$ embora Casearia tenha sido a mais eficiente fotossinteticamente no uso do P.

\section{REFERENCIAS}

1. Ayres, M.; Ayres Junior, Ayres, D.L. \& dos Santos,A .S. - BioEstat 3.0. Aplicações estatísticas nas áreas das Ciências Biológicas e Médicas. Sociedade Civil Mamirauá/MCT-CNPQ/ Conservation International, Belém, Pará. 2003.

2. Fortini, L. B., Mulkey, S.S., Zarin, D., Vasconcelos, S.S. e Carvalho, C.J.R.- Drought constraints on leaf gas exchange by Miconia ciliata ( Melastomataceae) in the understory of eastern Amazonian Regrowth Forest Stand. American Journal of Botany, 90 (7):1064-1070. 2003

3. Gamon. J.A.; Serrano, L. e Surfus, J.S. - The photoquemical reflectance index: an optical indicator of photosynthetic radiation use efficiency across species, functional types and nutrient levels. Oecologia, v.112, n.4; p.492-501. 1997

4. Halsted, M. e Lynch, J. - Phosphorus responses of C3 and C4 species. Journal of Experimental Botany, 47, pp.497-505. 1996

5. Hikosaka K. \& Hirose, T.- Photsynthetic Nitrogen-use efficiency in evergreen broadleaves woody species coexisting in a warm-temperate forest. Tree Physiology, Canadá, 20:1249-1254. 2000

6. Hiremath, A. 2000 - Photosynthetic nutrient-use efficiency in three fast-growing tropical trees with differing leaf longevities. Tree Physiology, Canada, 20:937-944.

7. Lostau, D.; Brahim, MB; Gaudillère, J.P. e Dreyer, E.- Photosynthetic responses to phosphorus nutrition in two-year-old maritime pine seedlings. Tree Physiology, Heron Publishing, Canadá, 39:pp.707-715. 1999

8. Pieters, A. J.; Paul, M.J.; Lawlor, D. W.2001- Low sink demand limits photosynthesis under $P_{i}$ deficiency. Journal of Experimental Botany, 52:358, 1083- 1991.

9. Rosati, A ., Esparza ,G., Dejong, T. M. e Pearcy, R. W - Influence of canopy light environment and nitrogen availability on leaf photosynthetic characteristics and photosynthetic nitrogen-use efficiency of field-grown nectarine trees. Tree Physiology, Canadá, 19:173-180. 1999 